\title{
Esportes de aventura praticados na Barra da Tijuca e São Conrado, RJ: um levantamento das modalidades e formação do instrutor
}

\section{RESUMO}

Buscou-se identificar e analisar quais são os esportes de aventuras mais praticados na Barra da Tijuca e São Conrado, bem como a formação dos instrutores responsáveis pela condução dessa vertente esportiva nos referidos espaços naturais do Rio de Janeiro. A partir de um estudo de campo, com um grupo amostral de 176 instrutores foi possível afirmar que os esportes de aventura mais praticados são voo livre $(81 \%)$, kitesurf $(7 \%)$, surf $(5 \%)$, trilha $(5 \%)$, rapel $(2 \%)$ e escalada $(1 \%)$. Quanto à formação profissional, a investigação permite sinalizar que apenas $14 \%$ do total de instrutores possuíam formação em Educação Física. Portanto, o estudou concluiu que os esportes de aventura mais praticados nas regiões são os de mar e de montanha, além de desvelar a necessidade de formação em Educação Física, bem como cursos de capacitação de instrutores de esportes de aventura, bem como auxiliar na formação daqueles que têm interesse por atuação nesse campo.

PALAVRAS-CHAVE: Esporte; Educação física; Formação de professores; Instrutor
Felipe da Silva Triani

Doutorando em Ciências do Exercício e do

Esporte

Universidade do Estado do Rio de Janeiro - UERJ

Programa de Pós-Graduação em Ciências do

Exercício e do Esporte

Rio de Janeiro, Rio de Janeiro, Brasil felipetriani@gmail.com

https://orcid.org/0000-0001-6470-8823

Bruno Henrique Ribeiro Sampaio

Bacharel em Educação Física

Centro Universitário Gama e Souza Instituto de Biociências

Rio de Janeiro, Rio de Janeiro, Brasil

brunoribeiro.contato@hotmail.com

https://orcid.org/0000-0003-0091-9175

Leonardo Mota de Castro

Bacharel em Educação Física

Centro Universitário Gama e Souza

Instituto de Biociências

Rio de Janeiro, Rio de Janeiro, Brasil

leonardoprofperso.al@outlook.br

https://orcid.org/0000-0002-1825-0097

Jairo Antônio da Paixão

Doutor em Ciências do Desporto

Universidade Federal de Viçosa - UFV

Programa de Pós-graduação em Educação

Viçosa, Minas Gerais, Brasil

jairopaixao2004@yahoo.com.br

https://orcid.org/0000-0002-8251-5985 


\title{
Adventure sports practiced in Barra da Tijuca and São Conrado, RJ: a survey of the modalities and training of the instructor
}

\begin{abstract}
We sought to identify and analyze the most practiced adventures sports in Barra da Tijuca and São Conrado, as well as the training of the instructors responsible for conducting this sport aspect in the aforementioned natural spaces of Rio de Janeiro. From a field study, with a sample group of 176 instructors, it was possible to state that the most practiced adventure sports are free flight $(81 \%)$, kite surfing $(7 \%)$, surfing $(5 \%)$, rappelling $(2 \%)$ and climbing $(1 \%)$. As far as professional training is concerned, research shows that only $14 \%$ of the total number of instructors had physical education. Therefore, the study concluded that the most practiced adventure sports in the regions are the sea and mountain, as well as unveiling the need for physical education training, as well as training courses for adventure sports instructors, as well as for training those who are interested in acting in this field.
\end{abstract}

KEYWORDS: Sport; Physical education; Teacher training; Instructor

\section{Deportes de aventura practicados en Barra da Tijuca y São Conrado, RJ: un levantamiento de las modalidades y formación del instructor}

\section{RESUMEN}

Se buscó identificar y analizar cuáles son los deportes de aventuras más practicados en la Barra da Tijuca y São Conrado, así como la formación de los instructores responsables por la conducción de esa vertiente deportiva en los referidos espacios naturales de Río de Janeiro. A partir de un estudio de campo, con un grupo muestral de 176 instructores fue posible afirmar que los deportes de aventura más practicados son vuelo libre $(81 \%)$, kitesurf $(7 \%)$, surf $(5 \%)$, trilha $(5 \%)$, rapel $(2 \%)$ y escalada (1\%). En cuanto a la formación profesional, la investigación permite señalar que sólo el 14\% del total de instructores poseían formación en Educación Física. Por lo tanto, el estudio concluyó que los deportes de aventura más practicados en las regiones son los de mar y montaña, además de desvelar la necesidad de formación en Educación Física, así como cursos de capacitación de instructores de deportes de aventura.

PALABRAS-CLAVE: Deporte; Educación física; Formación de profesores; entrenador 


\section{INTRODUÇÃO}

Entende-se por esporte de aventura o conjunto de práticas corporais realizadas nos diferentes ambientes naturais como o aéreo, o terrestre e o aquático que têm como aspecto comum o elemento risco, que dependendo da modalidade e das condições como é praticada, pode manifestar-se em proporções variadas (COICEIRO, 2007; PAIXÃO; TUCHER, 2010). Trata-se de uma vertente esportiva que se encontra numa crescente inserção em diversos contextos sociais como, por exemplo, educacionais, lazer e de rendimento (COSTA; MARINHO; PASSOS, 2007). Dentre os fatores que contribuem para se entender a expansão do esporte de aventura na ambiência social contemporânea, destacam-se a crescente demanda de o homem (r)estabelecer contato com a natureza, da busca por sensações e fortes emoções a partir de novos modos de viver o tempo livre numa sociedade demasiado rotineira, controladora, dessacralizada e laica. Como profusão desses fatores, vive-se uma espécie de movimento social que transformou atividades alternativas em um mercado esportivo e de turismo que, por sua vez, vem proporcionado uma crescente visibilidade aos esportes de aventura (MOURA; SOARES, 2014).

Nesse contexto, destaca-se a cidade do Rio de Janeiro que, embora seja capital do estado e todas as características de ambiente urbano estejam presentes, suas especificidades naturais compõem um universo de possibilidades de manifestação dos esportes de aventura. Dias e Alves Júnior (2007a, p. 40) destacam que no Rio de Janeiro a exibição pública dos corpos e o esporte desempenham um papel-chave e, por essa razão, não é difícil entender o motivo pelo qual a cidade é conhecida por "capital brasileira das montanhas e símbolo do surfe nacional”. Esses autores afirmam ainda que, apesar da ausência de estudos históricos mais aprofundados, tudo indica que o Rio de Janeiro foi o porto de entrada para algumas modalidades de esporte de aventura no Brasil, como o voo livre, em 1974 (DIAS; ALVES JUNIOR, 2007a).

Como uma das características que permeia as diversas modalidades de esporte de aventura, o risco objetivo configura-se elemento que exerce sentimentos marcados pelo antagonismo entre os seus praticantes, ora os aproximando, ora os distanciando de vivenciar fortes sensações como vertigem, adrenalina e liberdade. Sob essa ótica antagônica, destaca-se Almeida (2008) ao afirmar que nas modalidades de esporte de aventura, o risco é um elemento que possibilita uma sociabilidade entre os praticantes, o que, por sua vez, enfrentam situações de vulnerabilidade de diferentes magnitudes, como quedas, colisões, escoriações, fraturas, afogamentos, mal-estar, entre outros (ASHCROFT, 2001). Atenta às crescentes visibilidades e difusão do esporte de aventura nos diferentes espaços naturais no país, Spink (2002) assinala que se, por um lado, é necessário garantir 
padrões de segurança para a prática da referida vertente esportiva, por outro, é indispensável garantir a percepção do risco ao praticante. Nessa direção, a autora acredita na possibilidade de minimizar os riscos através da adoção de equipamentos de segurança credenciados por órgãos internacionais de segurança, e a experiência e treinamento dos responsáveis pela condução dessas práticas corporais na natureza (SPINK, 2004).

Embora a experiência e treinamento do profissional responsável pela condução das modalidades de esporte de aventura configura-se condição indispensável para aumentar a percepção sobre a segurança nas diversas modalidades dessa vertente esportiva, tem-se percebido a inexistência de um perfil profissional para esse segmento esportivo no país (COSTA, 2006). Nessa direção, é importante assinalar um estudo realizado por Paixão e Tucher (2010) em que foi analisado o perfil dos instrutores de esporte de aventura atuantes no estado de Minas Gerais. Os dados mostraram a inexistência de uma formação sistematizada, em que a atuação como instrutores tem-se fundamentado unicamente na experiência pregressa do instrutor enquanto praticante em uma ou mais modalidades. Com isso, foram encontrados instrutores com diferentes níveis de formação, variando de educação básica à graduação em diferentes áreas do conhecimento.

Tendo em vista as especificidades que caracterizam as diversas modalidades de esporte de aventura praticadas em diferentes ambientes naturais, bem como as demandas que incidem sobre o instrutor que se encontra responsável pela condução dessas práticas corporais, seja no âmbito do lazer e/ou da competição, suscitam reflexões sobre o tipo de atuação do profissional que conduz as modalidades de esporte de aventura que se fazem presente na ambiência natural do Rio de Janeiro e de muitas outras regiões, haja vista a riqueza em termos de dimensão e diversidade geográfica que dispõe o país.

Nessa perspectiva, o objetivo do presente estudo foi identificar e analisar os esportes de aventura mais praticados na Barra da Tijuca e São Conrado, bem como a formação profissional dos instrutores responsáveis pela condução dessa vertente esportiva nos referidos espaços naturais na cidade do Rio de Janeiro.

\section{METODOLOGIA}

O presente trabalho caracteriza-se como um estudo descritivo-exploratório (THOMAS, NELSON; SILVERMAN, 2012), que tem como características observar, registrar, analisar, descrever, correlacionar fatos ou fenômenos sem manipulá-los. Trata-se de uma pesquisa de campo que, de acordo com Severino (2007), é aquela em que a coleta dos dados se dá nas condições 
naturais em que os fenômenos ocorrem, sendo assim diretamente observados, sem intervenção e manuseio por parte do pesquisador. Abrange desde os levantamentos, que são mais descritivos, até estudos mais analíticos (SEVERINO, 2007).

Como procedimentos adotados para a coleta de dados, utilizou-se a técnica de observação que, conforme Sampieri, Collado e Lucio (2013), faz referência ao registro sistematizado de elementos do cotidiano que podem ser observáveis pelo pesquisador. Dessa maneira, para auxílio da atividade de campo, os pesquisadores utilizaram um roteiro de observação de campo que continha os seguintes elementos: local onde a prática estava sendo realizada, modalidade de esporte de aventura e número de instrutores. Adicionalmente, foi empregada a técnica "cliente oculto" (MORRISON; COLMAN; PRESTON, 1997), na qual o pesquisador se apresenta como possível cliente, ocasião em que o pesquisador pergunta ao atendente algumas informações sobre o serviço oferecido, dentre eles, os que atendem ao seu objetivo específico. No caso da presente investigação, os pesquisadores buscaram saber por meio dessa técnica o número de instrutores atuantes naquela ambiência e se tinham formação em Educação Física.

Para os fins específicos de desenvolvimento dessa pesquisa, o grupo amostral foi constituído de 176 instrutores de esporte de aventura, todos do sexo masculino, com média de idade entre 36 anos, atuantes nas regiões da Barra da Tijuca e São Conrado na cidade do Rio de Janeiro. A escolha foi intencional, pois se trata de regiões que, em decorrência das diferenciações e extensões geográficas, permitem a prática de modalidades de esporte de aventura comuns a diferentes espaços naturais como 1) terrestres: escalada, rapel e trilha; 2) aéreas: parapente e asa delta; 3) aquáticas: "surf" e "kitesurf". Aliado a esses fatores, encontrava-se a necessidade de se delimitar a amostra.

$\mathrm{Na}$ definição dos participantes da pesquisa foram adotados os seguintes critérios de inclusão: atuar como instrutor de modalidades de esporte de aventura nas regiões da Barra da Tijuca e São Conrado na cidade do Rio de Janeiro, concordar em participar da pesquisa e ter assinado as duas vias do Termo de Consentimento Livre e Esclarecido (TCLE). Enquanto que os de exclusão foram: o não enquadramento dos possíveis participantes nas condições ressaltadas, bem como o não interesse em participar da pesquisa.

Em síntese, os procedimentos para a coleta de dados foram realizados por dois pesquisadores que possuem conhecimento sobre as referidas técnicas. Inicialmente, foi realizado um levantamento das modalidades oferecidas nas regiões por meio de páginas na internet, redes sociais e cartazes espalhados, com o objetivo de conhecer os esportes oferecidos e os horários em que aconteciam. Em seguida, foram marcadas as visitas ao espaço de prática das modalidades. Durante a visita, um dos pesquisadores ficou responsável em realizar a técnica de observação e registro das informações, e o outro por fazer contato pessoal com o responsável pelo serviço, 
aplicando a técnica "cliente oculto". Os procedimentos descritos foram realizados em apenas uma visita, nos locais que ocorriam as práticas das modalidades de esporte de aventura, no período de março e maio de 2018. Cabe assinalar que todos os participantes foram devidamente informados sobre a pesquisa, conforme exigências contidas na Resolução 510/16 que trata dos aspectos éticos em pesquisa com humanos.

Os dados da pesquisa resultantes das observações realizadas nos espaços naturais onde se efetivavam as práticas das modalidades de esporte de aventura foram tabelados em uma planilha no Excell ${ }^{\circledR}$ para composição de um banco de dados. Nesse sentido, concluída a coleta de dados, os resultados foram sistematizados para apresentação das modalidades mais praticados nas regiões, bem como a distribuição em valores percentuais da formação dos instrutores.

No decorrer do processo de condução desta pesquisa, foram respeitadas as diretrizes regulamentadas pela Resolução $n^{\circ} 510 / 16$ da CONEP, sendo o projeto aprovado pelo Comitê de Ética em Pesquisa da Universidade do Grande Rio (UNIGRANRIO), ofício CEP Nº 2.072 .798 de 19 de maio de 2017. Para o conteúdo das ilustrações, tabelas e quadros utilize fonte tamanho $11 \mathrm{em}$ espaçamento simples.

\section{RESULTADOS E DISCUSSÃO}

A presente seção desenvolveu-se através da triangulação entre os dados obtidos, a bibliografia especifica e, também, as posições assumidas pelos autores da investigação em relação ao fenômeno. Dessa forma, foi possível uma compreensão e discussão das categorias de análise que se encontram organizadas em duas partes: a primeira busca identificar as modalidades de esporte de aventura mais praticadas nas regiões da Barra da Tijuca e São Conrado, na cidade do Rio de Janeiro; a segunda parte caracteriza o instrutor que atua nessas regiões, tendo em vista sua formação e modalidade de esporte de esporte de aventura. 
Figura 1 - Esportes de aventura praticados nos bairros da Barra da Tijuca e São Conrado no Rio de Janeiro.

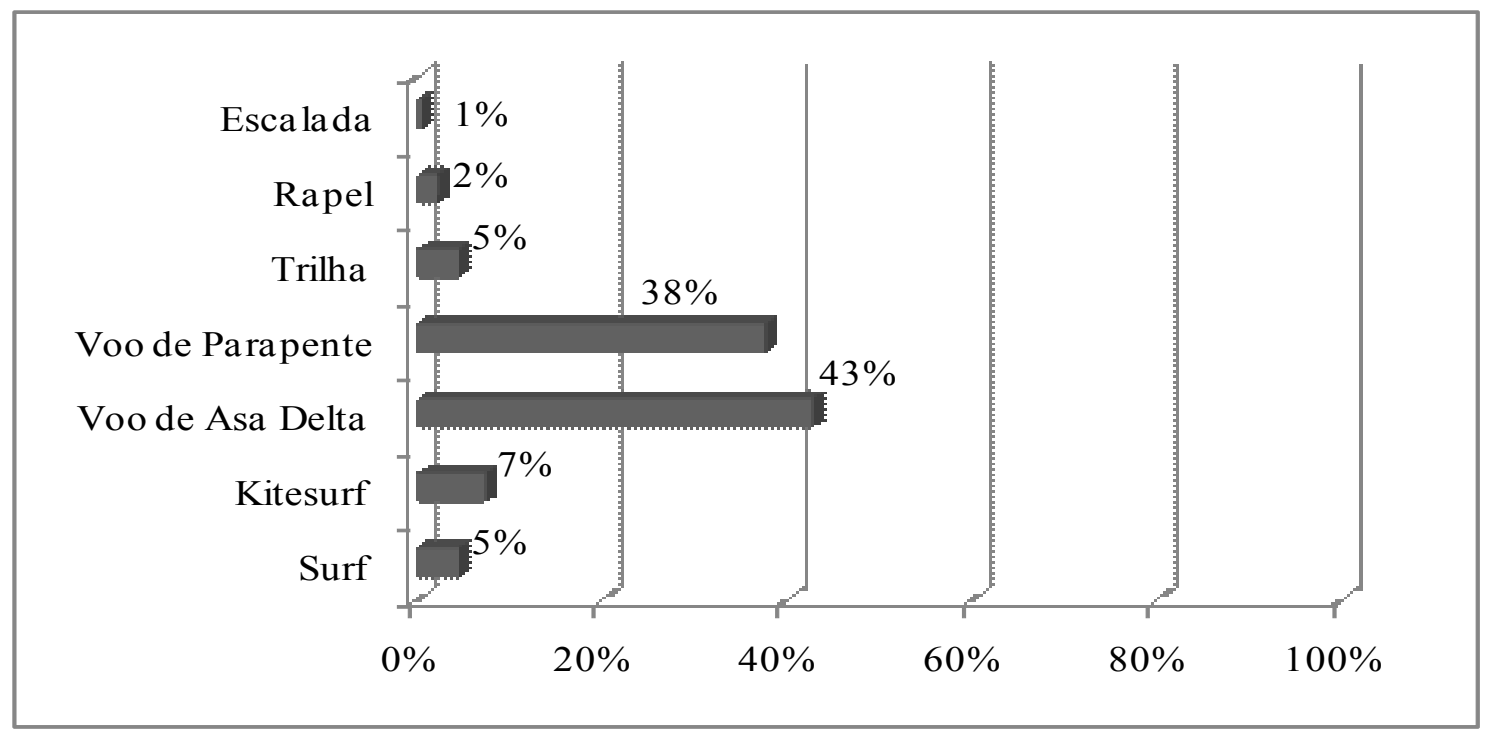

Fonte: os autores.

Com relação às modalidades de esporte de aventura mais praticadas nas regiões da Barra da Tijuca e São Conrado, conforme os resultados apresentados na Figura 1, destacam-se aquelas praticadas nas três ambiências naturais como terrestre: escala, rapel e trilha; aquática: kitesurf e surf, e aérea: parapente e asa delta. Dentre essas modalidades, a maior prevalência em termos de frequência de prática ficou entre aquelas da ambiência aérea, sendo a asa delta com $43 \%$ e o parapente com $38 \%$.

A asa delta e o parapente são duas modalidades que compõe o esporte voo livre. Em termos históricos, Dias e Alves Júnior (2007b) assinalam que essa prática chegou à cidade do Rio de Janeiro em meados de 1974 e, de acordo com a Confederação Brasileira de Voo Livre (s/d), possivelmente, o primeiro voo foi feito no local onde atualmente é a rampa de São Conrado. Dessa forma, é possível assinalar que no contexto brasileiro, a prática do voo livre no Brasil tem como berço a cidade do Rio de Janeiro, fato que pode ser uma explicação plausível para ser um dos esportes de aventura mais prevalentes na região.

De acordo com Dias e Alves Júnior (2007b), o cenário brasileiro conta com aproximadamente 180 pontos de salto espalhados por todo o país, sendo um deles na cidade do Rio de Janeiro, intitulado de rampa da Pedra Bonita, mais conhecida como rampa de São Conrado. Esses dados permitem afirmar que o local visitado pelos pesquisadores é o mais antigo do Brasil e o único local de prática com autorização do Rio de Janeiro. Há outras ambiências clandestinas em que a prática é vista, no 
entanto, somente a rampa de São Conrado tem autorização da Associação Brasileira de Voo Livre, sendo condicionada e regularmente cadastrada pelo Serviço Regional de Aviação Civil.

Nessa perspectiva, o fato do estudo ter observado o voo livre como esporte de aventura com a maior prevalência de prática na cidade do Rio de Janeiro pode ocorrer porque a rampa de São Conrado é o único e o mais antigo da região, local para a prática do esporte na cidade. Dessa maneira, é importante destacar que embora essa vertente esportiva se manifeste na dimensão do lazer, trata-se de um equipamento cuja aquisição demanda vultosa quantia, o que por sua vez, configura-se fator limitante para uma grande parcela da sociedade brasileira.

Somam-se aos valores dos equipamentos os custos com o curso de piloto. Dessa maneira, devido ao alto custo para a prática da referida modalidade, muitos instrutores o realizam como uma atividade comercial, uma vez que é possível voar solo ou fazer voos duplos. No entanto, embora o comércio do voo livre seja proibido pela legislação, sua prática é permitida para instrução, sendo assim, os pilotos oferecem o serviço e o caracterizam como "atividade de instrução" (DIAS; ALVES JÚNIOR, 2007b).

No conjunto das modalidades praticadas nas regiões investigadas, é possível assinalar que o voo livre se mostrou a mais prevalente. Dentre os motivos que possam explicar essa prevalência encontram-se aqueles de natureza geográfica, cultural, o retorno financeiro às pessoas envolvidas direta e indiretamente como instrutores, e a população local. Embora sua prática esteja mais fortemente associada às questões empresariais, Moura e Soares (2014) apontam que a comercialização do voo livre, como esporte de aventura, foi um importante movimento social para propagação dos esportes de aventura.

O "kitesurf" figura-se com 7\% de prevalência, numa posição abaixo do voo livre dentre as modalidades praticadas nas regiões investigadas. De acordo com Pereira, Armbrust e Ricardo (2008), o "kitesurf" caracteriza-se como esporte praticado no meio misto, pois há uma fusão entre os meios aéreos e aquáticos para sua execução, necessitando de condições climáticas favoráveis tanto da água quanto do ar, fato presente no litoral brasileiro que favorece a prática do "kitesurf", implicando a possível prevalência de prática dessa modalidade (PAIXÃO; COSTA; GABRIEL, 2009).

Basicamente, a prática do "kitesurf" se dá a partir da utilização de uma prancha de windsurfe tracionada por um parapente, também conhecido como pipa, que possibilitará ao praticante executar manobras na água e no ar. Para tanto, essas manobras decorrem da combinação das técnicas denominadas propulsão, direção e equilíbrio com as condições climáticas (LUCENA; SILVA; BRASILEIRO, 2013).

A prática do kitesurf demanda de alto valor monetário, no que se refere à aquisição de equipamentos. Assim, considera-se o custo, assim como na grande parte dos esportes individuais ou 
de aventura, diferentemente do voo livre, enquanto atividade de empreendimento não rentável, restringindo-se a prática esportiva individual de lazer. Por essa razão, é cabível apontar aqui a relação entre atividade física e as condições socioeconômicas (RODRIGUES et al., 2017), uma vez que implicam a prevalência da prática esportiva, pois enquanto alternativa de lazer somente, o kitesurf é restrito, em grande parte, às classes sociais mais altas.

A trilha e o surf totalizam $10 \%$ (sendo 5\% para uma delas) da prevalência dentre as modalidades praticadas na região considerada na presente investigação. A presença dessas modalidades justifica-se pelo relevo que delineia a cidade do Rio de Janeiro. Como afirmam Dias e Alves Júnior (2007a), o Rio de Janeiro é conhecido como a cidade das montanhas e símbolo do surf nacional. No entanto, chama atenção a baixa prevalência de modalidades terrestres na região (PEREIRA, 2013).

Ao analisar a baixa prevalência dessas práticas é possível considerar que, quando comparada ao kitesurf e voo livre, apresentam maior acessibilidade em termos de condições socioeconômicas. Essa afirmação pode ser uma justificativa para compreender os motivos para a maior prevalência de oferta de serviços de voo livre e kitesurf e, baixa do surf e montanhismo, considerando que esses últimos possuem baixo custo para a prática (LIMA et al., 2018; TRIANI; SILVA; PAIXÃO, 2019), diferente do primeiro. Desse modo, a baixa prevalência da trilha e do surf pode ser explicada pelo fato de o kitesurf e voo livre configurarem-se como atrativos turísticos (DIAS; ALVES JÚNIOR, 2007a) da cidade, sendo esportes de aventura mais rentáveis, em termos de oferecimento do serviço por parte do instrutor, algo que ocorre em menor proporção na trilha e no surf, já que são práticas que, muitas vezes, são exequíveis sem instrução.

No que se refere à formação de instrutores que se encontram à frente na condução das modalidades de esporte de aventura praticadas nas regiões da Barra da Tijuca e São Conrado, considerando às questões concernentes à legislação, é observável no Estatuto do Conselho Federal de Educação Física (CONFEF, 2010) e na Lei 9.696 (BRASIL, 1998) que a intervenção sobre o esporte, independente das formas como se manifesta no âmbito do lazer e/ou competição, deverá ser exercida por profissional de Educação Física com formação específica em nível superior. No entanto, estudos na área (PAIXÃO, TUCHER, 2010; PAIXÃO, 2015) evidenciam que não há uma sistematização quando a formação dos instrutores de esportes de aventura, sendo essa uma característica dessa corrente esportiva.

Nesse contexto, dentre os objetivos definidos para a presente investigação, buscou-se conhecer a formação dos instrutores atuantes com modalidades de esporte de aventura nas regiões da Barra da Tijuca e São Conrado, conforme é apresentado na Tabela 1. 
Tabela 1 - Distribuição da atuação de Profissionais de Educação Física por esportes de aventura

\begin{tabular}{c|ccccccc}
\hline Esporte de Aventura & \multicolumn{2}{c|}{ Profissional de Educação Física } & \multicolumn{2}{c|}{ Outra formação } & \multicolumn{2}{c}{ Total } \\
\cline { 2 - 7 } & $\mathrm{N}$ & $\%$ & $\mathrm{n}$ & $\%$ & $\mathrm{n}$ & $\%$ \\
\hline Surf & 05 & 62,50 & 03 & 37,50 & 8 & $100 \%$ \\
Kitesurf & 0 & 0 & 13 & 100 & 13 & $100 \%$ \\
Voo de asa delta & 13 & 17,33 & 62 & 82,67 & 75 & $100 \%$ \\
Voo de parapente & 06 & 9,09 & 60 & 90,91 & 66 & $100 \%$ \\
Trilha & 0 & 0 & 08 & 100 & 8 & $100 \%$ \\
Rapel & 0 & 0 & 05 & 100 & 5 & $100 \%$ \\
Escalada & 0 & 0 & 01 & 100 & 1 & $100 \%$ \\
\hline
\end{tabular}

Fonte: os autores.

A Tabela 1 ilustra que dos 176 instrutores de esportes de aventura que participaram do presente levantamento realizado nas regiões, 24 (14\%) possuem graduação em Educação Física, e 152 (86\%) não possuem. Cabe assinalar que o objetivo da investigação em tela limitou-se a identificar se o instrutor do esporte de aventura possuía ou não o curso de formação superior em Educação Física, sendo assim, não fez parte da pesquisa questões concernente ao tipo de formação que os $86 \%$ possuem.

O entendimento dessa situação passa pela consideração das especificidades presentes nas diferentes modalidades de esporte de aventura, que as diferenciam daquelas modalidades consideradas clássicas como, por exemplo, o espaço natural como lócus excepcional no qual se concretizam as práticas, o elemento risco e as fortes emoções. Soma-se a isso, conforme identificado em um estudo anterior (PAIXÃO; TUCHER, 2010) que, dentre os principais motivos que colaboram para a decisão do indivíduo atuar como instrutor de esporte de aventura, bem permanecer nessa categoria profissional, se fundamenta nas experiências práticas em uma ou mais modalidades na condição de praticante.

Nessa direção, ainda que o Estatuto do Conselho Federal de Educação Física recomenda que a trato com as modalidades de esporte sejam realizadas por professores com formação em Educação Física, é preciso reconhecer que, devido às especificidades que configuram as modalidades de esporte 
de aventura em espaços naturais distintos, seria inviável nas matrizes curriculares dos cursos de formação inicial do professor de Educação Física, uma ou mais disciplinas que fossem capazes de atender a todas as manifestações dessa vertente esportiva, e preparar esse profissional para uma atuação condizente às demandas impostas (BRASIL et al., 2015).

Para algumas modalidades, tem-se formações especificas acessíveis às pessoas de diferentes formações como paraquedismo, voo livre, surf e outras. Como assinala Brasil e outros (2015), desde a década de 1980 há cursos de nível internacional para treinadores de surf e, no contexto brasileiro, as primeiras iniciativas datam de 2003 por meio do Instituto Brasileiro de Surf. Esses cursos de formação têm ênfase na segurança e na qualidade da orientação oferecida.

O voo livre, esporte de maior oferta nas regiões, possui 19 profissionais de educação física e 122 instrutores sem formação em educação física. No entanto, em termos de formação profissional, de acordo com Dias e Alves Júnior (2007b), o voo livre está submetido às regulamentações do Departamento de Aviação Civil, em que somente pode praticar o esporte quem tenha habilitação para a prática. Essa habilitação divide-se em seis níveis: aluno, novato, intermediário, avançado, máster e instrutor. Dessa maneira, torna-se necessário realizar um curso ministrado por um piloto com habilitação de instrutor credenciado junto à Associação Brasileira de Voo Livre, nível seis, para praticar o voo livre. Logo, como teoricamente não é possível praticar o esporte sem ser piloto, o que faz com que muitos instrutores oferecem o voo duplo como atividade comercial e a registram como "voo de instrução", prática permitida.

Em relação ao kitesurf, trilha, rapel e escalada não foram encontrados nenhum instrutor com graduação em Educação Física. Paixão (2015) assinala que o perfil da prática dessa corrente esportiva está marcada pelos procedimentos e estratégias advindos de experiências na modalidade enquanto praticante, já Costa (2000) ressalta que, no contexto brasileiro, ainda não ocorreu a profissionalização do instrutor de esporte de aventura. Nesse contexto, Paixão (2015) alerta que a falta de formação específica para esses instrutores pode, entre outras condições, implicar a submissão do praticante à situação de vulnerabilidade ao risco, e que haja necessidade de normatização da formação do instrutor do esporte de aventura.

O presente estudo embora tenha se limitado em levantar os esportes de aventura praticados somente em dois bairros da cidade, explorou a única rampa de voo livre de todo o Rio de Janeiro, algo que permitiu mapear o quantitativo de instrutores de asa delta e parapente com e sem formação em Educação Física na ocasião da pesquisa.

\section{CONCLUSÃO}


A investigação em tela demonstra que as regiões da Barra da Tijuca e São Conrado, na cidade do Rio de Janeiro, são espaços em que há prática de diferentes esportes de aventura, não somente por serem ambientes naturais favoráveis para a prática dessa corrente esportiva, mas também por sofrer influências sociais e histórias no que concerne à algumas modalidades.

Foi possível identificar por meio da pesquisa que seis esportes de aventura são comumente praticados nesses espaços, sendo eles o surf, kitesurf, voo livre, trilha, rapel e escalada. Essas modalidades de esportes de aventura são oportunizadas considerando as regiões de mar e montanha que circundam os bairros Barra da Tijuca e São Conrado.

O estudo também identificou que dentre o total de instrutores de esportes de aventura responsáveis por conduzir a prática, menos de $15 \%$ possuem formação em educação física. Nessa perspectiva, parece que nas regiões onde o levantamento foi realizado, há necessidade de formação de professores de Educação Física para atuação nesse viés de mercado profissional, que é o esporte de aventura, caracterizando-se como área promissora, já que atualmente grande parte dos instrutores não possui formação em Educação Física.

É recomendável que as entidades como as confederações e federações caminhem no sentido propiciar a formação de pessoas que vem atuando como instrutores de esporte de aventura, visando não somente uma estandardização, como ainda o atendimento integral daqueles que venham a se interessar em instruir-se numa ou mais modalidades dessa prática corporal no país.

Como observação final, adverte-se para a necessidade de realização de novas pesquisas abarcando outros aspectos vinculados ao trabalho do instrutor de esporte de aventura em outros espaços naturais de prática, com especificidades distintas das apresentadas neste estudo.

\section{REFERÊNCIAS}

ALMEIDA, Luiz Guilherme Veiga. Ritual, risco e arte circense: o homem em situações limites. Brasília: UnB, 2008.

ASHCROFT, Frances. Life at the extremes: the science of survival. London: Harper Collins, 2001.

BRASIL. Lei n. 9.9696, de 1 de setembro de 1998. Dispõe sobre a regulamentação da Profissão de Educação Física e cria os respectivos Conselho Federal e Conselhos Regionais de Educação Física. Brasília, DF, Diário Oficial da União, 1998.

BRASIL, Vinicius Zeilmann; RAMOS, Valmor; Milistetd; GALATTI, Larissa; VIANA, Juarez. A formação profissional para treinadores de surf no Brasil. In. NASCIMENTO, Juarez Vieira; 
SOUZA, Edison Roberto.; RAMOS, Valmor; ROCHA, Júlio César Schimitt. (Orgs.). Educação Física e Esporte: convergindo para novos caminhos. Florianópolis: Editora da UDESC, 2015.

COICEIRO, Geovana Alves. O imaginário social de aventureiros do extremo: o universo simbólico dos praticantes de provas de ultraresistência. 2007. 236 f. (Tese de Doutorado em Educação Física) UGF, Rio de Janeiro, 2007.

CONFEF. Estatuto do conselho federal de educação física. Diário Oficial, Brasília, n. 237, p. 137$143,2010$.

COSTA, Vera Lucia Menezes. Esportes de aventura e risco calculado na montanha: um mergulho no imaginário. São Paulo: Manole, 2000.

COSTA, Vera Lucia Menezes; MARINHO, Alcyane; PASSOS, Katia Cristiana Montenegro. Esportes de aventura e esportes radicais: propondo conceitos. Motriz, vol. 13, n. 2, (Supl.1), p. 44343, 2007.

DIAS, Cleber Augusto Gonçalves; ALVES JUNIOR, Edmundo de Drummond. Entre o mar e a montanha: esporte, aventura e natureza no Rio de Janeiro. Niterói: EdUFF, 2007a.

DIAS, Cleber Augusto Gonçalves; ALVES JUNIOR, Edmundo de Drummond. O Voo livre no Rio de Janeiro: uma visão panorâmica. Revista Digital EFDeportes, Buenos Aires, vol. 11, n. 105, $2007 b$.

LIMA, Marcio da Silva Xavier; TRIANI, Felipe da Silva; SEIXAS FILHO, José Teixeira; MOREIRA, Jorge Felipe Fonseca. Esportes de aventura: algumas possibilidades na região da Barra de Guaratiba no Rio de Janeiro, Semioses, vol. 12, n. 1, p. 36-45, 2018.

LUCENA, Angélica Brasileiro; SILVA, Priscilla Pinto Costa; BRASILEIRO, Maria Dilma Simões. A prática do kitesurf e o universo da preservação ambiental. Licere, vol. 16, n. 1, p. 1-18, 2013.

MORRISON, Lisa; COLMAN, Andrew; PRESTON, Carolyn. Mystery customer research: cognitive processes affecting accuracy. Journal of the Market Research Society, vol. 39, p. 349$361,1997$.

MOURA, Diego Luz; SOARES, Antônio Jorge. Esporte de risco e risco no esporte: uma análise do risco percebido no voo livre. Revista Educação Física da UEM, Maringá, vol. 25, n. 1, 2014.

PAIXÃO, Jairo Antônio. Entre a aventura e o risco: formação e atuação profissional de instrutores de esporte de aventura no Estado de Minas Gerais. Revista Mackenzie de Educação Física e Esporte, São Paulo, vol. 14, n. 1, p. 257-271, 2015.

PAIXÃO, Jairo Antônio; COSTA, Vera Lucia Menezes; GABRIEL, Ronaldo Eugênio Calçada Dias. Esporte de aventura e ambiente natural: dimensão preservacional na sociedade de consumo. Motriz, vol. 15, n. 2, p. 367-373, 2009.

PAIXÃO, Jairo Antônio.; TUCHER, Guilherme. Risco e aventura por entre as montanhas de minas: a formação do profissional de esporte de aventura. Pensar a Prática, Goiânia, vol. 13, n. 3, 2010. 
PEREIRA, Dimitri Wuo. Montanhismo e Escalada. In.: BERNARDES, Luciano. (Org.). Atividades e esportes de aventura para profissionais de Educação Física. São Paulo: Phorte, 2013.

PEREIRA, Dimitri Wuo; ARMBRUST, Igor; RICARDO, Denis Prado. Esportes radicais, de aventura e ação: conceitos, classificações e características. Revista Corpoconsciência, vol. 12, n. 1, p. 18-34, 2008.

RODRIGUES, Philipe Ferreira; MELO, Marcelo; ASSIS, Monique Ribeiro; PALMA, Alexandre. Condições socioeconômicas e prática de atividades físicas em adultos e idosos: uma revisão sistemática. Revista Brasileira de Atividade Física e Saúde, vol. 22, n. 3, p. 217-232, 2017.

SAMPIERI, Roberto Hernandez; COLLADO, Carlos Fernández; LUCIO, María Pilar Baptista. Metodologia de pesquisa, $5^{\text {a }}$ ed. São Paulo: Artmed, 2013.

SEVERINO, Antonio Joaquim. Metodologia do Trabalho Científico. 23. Ed. São Paulo: Cortez, 2007.

SPINK, Mary Jane. Suor, Arranhões e Diamantes: as contradições do risco na modernidade reflexiva. http://www.ensp.fiocruz.br/projetos/esterisco/ index.htm, 2002.

SPINK, Mary Jane; GALINDO, Dolores; CANAS, Antonio; SOUZA, Daniella. Onde está o risco? Os seguros no contexto do turismo de aventura. Psicologia \& Sociedade, vol. 16, n. 2, p. 81-89, 2004.

THOMAS, Jerry; NELSON, Jack.; SILVERMAN, Stephen. Métodos de pesquisa em atividade física. $6^{\mathrm{a}}$ ed., Porto Alegre: Artmed, 2012.

TRIANI, Felipe da Silva; SILVA, Felipe Tomaz; PAIXÃO, Jairo Antônio. Escalada indoor como possibilidade de conteúdo para a educação física escolar. Conexões, vol. 17, 1, p. e019036, 2019.

\section{NOTAS DE AUTOR}

\section{AGRADECIMENTOS}

Não se aplica.

\section{CONTRIBUIÇÃO DE AUTORIA}

Não se aplica.

FINANCIAMENTO

Não se aplica.

CONSENTIMENTO DE USO DE IMAGEM

Não se aplica. 
A pesquisa oi aprovada pelo Comitê de Ética em Pesquisa da UNIGRANRIO, sendo o número do parecer 2.072.798, com data de 19 de maio de 2017.

\section{CONFLITO DE INTERESSES}

Não se aplica.

\section{LICENÇA DE USO}

Os autores cedem à Motrivivência - ISSN 2175-8042 os direitos exclusivos de primeira publicação, com o trabalho simultaneamente licenciado sob a Licença Creative Commons Attribution Non-Comercial ShareAlike (CC BY-NC SA) 4.0 International. Esta licença permite que terceiros remixem, adaptem e criem a partir do trabalho publicado, desde que para fins não comerciais, atribuindo o devido crédito de autoria e publicação inicial neste periódico desde que adotem a mesma licença, compartilhar igual. Os autores têm autorização para assumir contratos adicionais separadamente, para distribuição não exclusiva da versão do trabalho publicada neste periódico (ex.: publicar em repositório institucional, em site pessoal, publicar uma tradução, ou como capítulo de livro), com reconhecimento de autoria e publicação inicial neste periódico, desde que para fins não comerciais e compartilhar com a mesma licença.

\section{PUBLISHER}

Universidade Federal de Santa Catarina. Programa de Pós-Graduação em Educação Física. LaboMídia - Laboratório e Observatório da Mídia Esportiva. Publicado no Portal de Periódicos UFSC. As ideias expressadas neste artigo são de responsabilidade de seus autores, não representando, necessariamente, a opinião dos editores ou da universidade.

\section{EDITORES}

Mauricio Roberto da Silva, Giovani De Lorenzi Pires, Rogério Santos Pereira.

\section{HISTÓRICO}

Recebido em: 20 de Fevereiro de 2019.

Aprovado em: 22 de Outubro de 2019. 